\title{
Research on the life oriented mathematics teaching in primary school
}

\author{
Pu Zhang ${ }^{1,}$ a, Heyi Tang', b \\ 1,2 Hubei science and Technology College, HuBei 437100, China \\ a21844742@qq.com, b327708125@qq.com
}

Keywords: Mathematics Teaching,Life

\begin{abstract}
Life is education, education is life" reveals the close relationship between education and life, and mathematics education as an important branch of education, but also with human development and social progress are closely related. Especially with the advent of the information society, it is the life of mathematics made a strong request. However, in actual teaching, the teaching of mathematics teaching and practical combination of most teachers did not attract attention. Therefore, this article will focus on the importance and necessity of mathematics teaching and the necessity of life, and the relevant situation of the research and analysis, based on the results of the study put forward the relevant implementation strategies of these three aspects.
\end{abstract}

Kailov, "education" in the definition: teaching is the cause of teachers, to maintain and promote students to learn all the way of behavior. Teaching is teachers' behavior, and is not the behavior of students; teachers' behavior including behavior (such as dialogue, counseling, etc.) and auxiliary behavior (such as bowel engine, teacher expectations, classroom interaction and classroom management) two categories.

Life teaching refers to teachers in the teaching process effectively combines teaching and daily life and social life organically, to the problems in teaching life, the life of the problem into the relevant teaching. So that students not only learn to consciously use learned to observe life analysis of the problems and solve them, and to learn from life to grasp the important knowledge and skills, achieve the goal which is to improve the students' consciousness of application and the spirit of innovation and practical ability."The primary school mathematics teaching in life" as mentioned above, the concept of "life oriented teaching" is essentially the same, but more emphasis on the characteristics of primary school and mathematics. Specifically refers to teachers based on the characteristics of primary school children's physical and mental development, to scenes of everyday life as a prototype to present mathematics knowledge, and guide students to independent mining mathematical problems in life and use the mathematics knowledge to solve.Through this show, reduce students with mathematical sense of distance, will enable the students to experience life in mathematics is everywhere, the mathematical knowledge can help us to solve real life problems, so that students can get a sense of achievement in learning mathematics, to stimulate interest in learning, helping students set up the "mathematics is derived from life, resides in life, for life" concept, train students to use mathematical knowledge to solve the problems of life habit and ability.

\section{Concrete case analysis: fractional multiplication}

For example to explain the application of fractional multiplication in this chapter, in order to allow students to realize that life is often applied to the fractional multiplication and scores can also help us to solve the problem of life.So, do the following design:

First of all, in the import link of students out of the box, and ask three students to report how many pens in the pencil case. In this link, to students around the life into the classroom, mainly in order to make this section draws close to the life, but also to students more easily into the situation 
and according to the actual situation to solve the problem.

Secondly, put forward the question: 1.the teacher's pen count is 1 / 2 of the Zhang San; 2, Xiao Ming pen count is $2 / 3$ of $\mathrm{Li} \mathrm{Si}$; Xiao Hong pen count is 4 / 5 of Zhangyang.Ask the students to think about the teacher, Xiao Ming, Xiao Hong, each have how many pens. This part puts forward the related problems, and students according to their own life experience can easily solve these problems. In the process of solution, let their own independent thinking, inquiry, so as to get the answer, both to enable them to actively participate in classroom learning, and can acquire and meet the desire to continue learning in the process of problem solving.

Again, analysis of the problem. In the process of problem analysis, and guide students found just in seeking to count the teacher's pen, what is the basis, this formula has what characteristic?Through the guide students to the first question analysis, leads to "unit 1" concept, so that the students can understand what is the basis to solve the problem, we put this basis is considered to be the "unit 1", by this way, make the abstract concept of specific, easy to the students understand, but also reduces the difficulty of student learning.Through the guide student's analysis of this formula is to guide students to find the meaning of this multiplication formula contains, and ultimately come to the conclusion: In our "unit 1 " is known, we can according to "unit 1 " to solve the problem.

Then practice the consolidation. With the basis of the above, and then a few related to the application of the problem to strengthen the students to practice. To enable students to practice in the process of thinking again to think, analyze the process, so as to consolidate the knowledge of learning.

Finally, review and summarize. The first is a simple review of the knowledge learned today.Then sum up the application of fractional multiplication in our life is also very wide, such as: shopping malls, discount problems, statistical problems, profitability, etc..The reason why in the final conclusion that fraction multiplication, the application problem, is to make students feel the knowledge of learning is not only to do exercises, more important is can be used for life and help us to solve the problems of life.

Through the teaching of this class can be found: for the associated with the life of teaching methods to help students quickly into the classroom, to understand the knowledge, also their participation, enthusiasm is high, the classroom teaching effect is relatively good.

\section{Strategies of life oriented mathematics teaching in primary school}

According to the needs of the development of mathematics education, we can see that the realization of teaching life is the inevitable trend of the development of mathematics education. Therefore, the author puts forward the following suggestions to help achieve the life of primary school mathematics teaching.

\section{Teachers to do "people who have a heart"}

As the main body and the designer, teachers play an important role in the development of teaching activities. Therefore, in order to realize the life of primary school mathematics teaching, we must give full play to the role of teachers. To this end, "teachers should do 'people"', mainly from the following two aspects:

A. the teacher should make the thought of "people"

Teachers here mentioned to thought "the person with high aspirations, mainly refers to the elementary school mathematics teachers need to constantly learn from the advanced education thought and educational idea, pay attention to the main trend of our primary school mathematics education development, and rational analysis on this trend logarithmic science education and social development can bring the positive influence, to from the thought with a positive attitude to recognize and accept the teaching idea, and be able to really think about how existing teaching 
adjustment for the life of the teaching methods, and truly realize the life oriented teaching of mathematics.

B. teachers should be the "heart" of the action "

First, teachers should careful observation of daily life and think about the math problems contained in the daily life, and the life situations to design and restructuring after the show in mathematics classroom, this way can enable students to be more familiar with the present situation, so as to enable them to participate in the enthusiasm is high, and more conducive to them on the basis of the existing life experience to solve problems in the classroom, feel the fun of learning mathematics. Secondly, teachers should be the guidance of mathematics classroom. In teaching, teachers should guide students to discover their own mathematical problems in life, to solve practical problems with the existing knowledge and life experience, in the process of mathematical problems in life, found that knowledge to solve mathematical problems, stimulate their curiosity, cultivate mathematics learning fun, while promoting they form an idea of mathematics and the life.Finally, teachers should also learn to use a variety of teaching methods to achieve the life of mathematics teaching. According to the psychological characteristics of primary school students, the use of vivid and interesting teaching methods to attract students' attention, stimulate students' interest in learning. Therefore, teachers can in the teaching process of make full use of visual objects, multimedia courseware, life situation simulation method to construct the students are familiar with the situation, let the students to experience the life and mathematics, and let the students experience to the joy of mathematics learning, let students is positive initiative to learn mathematics, to love mathematics.

\section{Adjust the content of teaching materials, close to the actual life}

Teaching material is an important carrier of learning, and it is an important reference for teachers to carry out teaching. Therefore, to realize the teaching life, we must make the appropriate adjustment to the teaching material content, make it more close to the actual life of the students, so as to help the realization of teaching life. Since the implementation of the new curriculum reform, in order to improve the students awareness of the application, many teaching cases in the new textbook presentation embodies the concept of living. We can see in the textbooks, both new course introduction, teaching examples or exercises arrangement on have the imprint of life.

\section{Fully mobilize the main role of the students}

In order to successfully realize the life of mathematics teaching, it can not be ignored the main role of students.For example, teachers can through organizing math games in the classroom to let students actively participate in class, then let the students in this process to mining related mathematical problems, so that the students in the process of the quest to find: Mathematics and life together, mathematics learning becomes a funny thing.Teachers can also will take students into small groups form and to group as a unit himself to preview the new knowledge, then independently explore new knowledge in the process to find the corresponding prototype, to group units to the students present their selected theme of life to explain new mathematical knowledge. In the process of group discussion, research, discovery and problem solving, students are able to find the knowledge, the familiar life situation and new knowledge construction to solve the new problems.

\section{Some problems to be noticed}

\section{Can not be completely equal to the mathematics of life}

Although we emphasize mathematics knowledge is to life as the prototype, advocated in the mathematics teaching reflect elements of life, emphasizing let life situations into the mathematics classroom, let the students in daily life to understand and learn mathematics, but it does not completely will equate mathematics and life.Life is only a medium to transfer mathematical knowledge, is to promote the role of mathematical knowledge of the catalyst, we can not blindly 
pursue the life of teaching methods to present mathematics and ignored the mathematical knowledge itself. Such as some teachers in the classroom blindly pursue present life situation to highlight the application of mathematical knowledge in life, students seem active discussion and participation in class, make mathematics classroom atmosphere is very active, but often in the process not classroom key knowledge highlights, make class straying from the subject, and ignore the cultivation of student's ability in other mathematics, from the mathematics learning, will eventually hinder the progress and development of mathematics education. Therefore, in the process of realizing mathematics teaching to life, to correctly grasp the differences between mathematics and life, let the life become a form of mathematics, mathematics becomes the life of tool, and cannot make life completely equivalent to mathematics.

\section{To avoid the form of life oriented Teaching}

We advocate the realization of life in mathematics teaching, but mathematics has its own way of thinking, spatial imagination and association with each other, it doesn't mean all the knowledge to find a prototype in our daily life.For example, grade four volumes of the observation object "is intended to train students space imagination ability, can let the student through observation to draw a planar graph. If you insist on the use life of the teaching way, every time the teacher class by real placed to allow students to observe and draw a planar graph, then this method will hinder students space imagination ability development. Therefore, in order to realize life cannot neglect their own mathematical knowledge. Teachers can not let the life form in the teaching process, hinders the development of students.

\section{The division of attention}

Children at different ages, their physical and mental development is also different. For example, in primary school lower grade school (grades 1-3) children, mainly to the specific image thinking, abstract thinking slow development. Primary school high grade school (grades 4-6), children's way of thinking is gradually from the concrete image thinking to abstract thinking development.Therefore, in the life oriented teaching mode should distinguish school period. Low grade primary school period should be mainly present life to teachers' teaching situation, to help build a life of low grade students with mathematics as the main way of contact. The high grade of primary school, the teacher should let students learn to build their own life and mathematics, teacher guidance and inspiration.

Primary school is the initial stage of mathematics learning, and it is an important stage to help students to build up the relationship between mathematics and life and to cultivate students' consciousness of application. In this paper, the author puts forward his views on mathematical problems of life teaching, perhaps some of the views is still not perfect, but in the future will further classroom teaching, continue to explore the life oriented teaching of primary school mathematics teaching methods, and strive for the further in practice to finish good theory, theory to better guide the practice.

\section{Item number:Ky14009}

\section{Reference}

[1] Feng Shurong, looking for mathematics from life, let mathematics return to life [J]. Heilongjiang Provincial Education Committee.2005

[2] Xie Tiejun. Teaching and research significance of mathematics concept under the background of new curriculum[D].Zhejiang Normal University.2012

[3] Zhou Xu. Educational philosophy on Dewey's [J]. Theory of learning.2013

[4] Xu Xinhai. Crisis and redemption of educational life [D]. Soochow University.2009

[5] Ministry of education. Nine years of compulsory education mathematics curriculum standards (Revised Version) [M]. Beijing Normal University press.2011 